\title{
Migraine strikes study: factors in patients' decision to treat early
}

\author{
Wendy Golden · Judith K. Evans $\cdot$ Henry Hu
}

Received: 17 October 2008/ Accepted: 5 December 2008/Published online: 10 January 2009

(C) Springer-Verlag 2008

\begin{abstract}
To describe factors associated with early treatment of migraine, and to examine reasons patients do not treat early, this cross-sectional observational study emailrecruited migraineurs $\geq 18$-years-old who were currently prescribed acute migraine medication. Within $24 \mathrm{~h}$ of migraine resolution, eligible patients completed an online migraine strikes questionnaire which addressed pain severity, associated symptoms, and other variables including reasons for not treating early. Results reported were descriptive. Among 1,044 evaluable patients, early treatment was significantly associated with several factors such as leisure activity at onset (OR 1.32, $P=0.010$ ), photophobia (OR $1.39, P=0.013)$, diagnosis of migraine with aura (OR 1.36 , $P=0.004)$, and other factors. Among 840 patients who reported wanting to treat earlier desire to reserve medication for a severe migraine was the most common reason given for not doing so $(51.2 \%)$. Overcoming these factors may facilitate earlier migraine treatment.
\end{abstract}

Authors Golden, Evans, and $\mathrm{Hu}$ are responsible for the work described in this paper. All authors were involved in at least one of the following: conception, design, acquisition, analysis, statistical analysis, interpretation of data, drafting the manuscript and/or revising the manuscript for important intellectual content. All authors provided final approval of the version to be published.

Electronic supplementary material The online version of this article (doi:10.1007/s10194-008-0091-1) contains supplementary material, which is available to authorized users.

W. Golden $(\bowtie) \cdot H . H u$

Outcomes Research Department, Global Human Health,

Merck and Co., Inc., Whitehouse Station, NJ 08889, USA

e-mail: wendy_golden@merck.com

J. K. Evans

Medical Communications, Merck Research Laboratories,

West Point, PA 19486, USA
Keywords Migraine - Triptans - Early treatment . Headache
Abbreviations
MIST Migraine strikes study
IRB Institutional Review Board
CHS Consumer Health Sciences International
OR Odds ratio
SD Standard deviation

\section{Introduction}

Migraine is a disabling disorder which affects about 30 million people in the United States [1]. Much research has been reported on the risk factors, triggers, premonitory symptoms, and concomitant symptoms associated with migraine attacks, such as nausea, photophobia, and visual disturbances [2-7]. Clinical and observational data from patients taking triptans have consistently demonstrated the benefits of treating early (i.e., at the onset of pain) [8-13], but despite this evidence, $69 \%$ of migraineurs report that they would not treat their migraine pain as soon as they feel pain [14]. In addition to issues regarding efficacy and potential side effects of triptans, other factors may affect patients' ability or willingness to treat early. This study investigated other such external environmental factors which may influence patients' decision to treat early, and factors which may prevent patients from treating a migraine as early as they desire.

\section{Methods}

Study design

This cross-sectional observational survey study [migraine strikes study (MIST)] was conducted from November to 
December 2006. A central Institutional Review Board (IRB) (ESSEX IRB, Lebanon, NJ) approved the study protocol, survey instrument, and the statement of informed consent. Consumer Health Sciences International (CHS), a contract research organization, provided each patient with full and adequate information about the objective and procedures of the study. Compensation was provided by the Lightspeed Consumer Panel to participants in the form of ceremonial "points," which patients were eligible to redeem at the panel's website for various retail products such as online gift certificates, music downloads, and kitchen appliances.

\section{Patients and procedures}

To be eligible for the study, patients had to be at least 18years-old and fluent in English. Patients had to have been diagnosed with migraine (with or without aura) by a physician, and had to have a current prescription for acute migraine medication(s). Patients were contacted via the internet to participate in the study. In an initial invitation email circular, patients were informed about the purpose and design of the study. If patients experienced a migraine attack within 7 days after they received the invitation email, they were invited to report their migraine experience within $24 \mathrm{~h}$ of its resolution. Patients accessed a passwordprotected web link attached in the initial email circular. Those who gave consent to participate were allowed to proceed to the migraine strikes questionnaire (Electronic supplementary Appendix 1).

In the migraine strikes questionnaire, participants reported circumstances of the migraine attack that occurred within the past $24 \mathrm{~h}$, such as the time and location in which the migraine occurred, and details about any therapy the patient used to treat the migraine. Information about migraine and other headache history was also collected. Consumer Health Sciences International fielded the study by setting up data programming for the migraine strikes questionnaire, tracking and monitoring patient's compliance with completing the questionnaire, and sending email reminders and thank you notes to participants. Consumer Health Sciences International collected the data, which was accessible only to research team members. Upon stripping the data of all patient-identifying information, CHS provided the sponsor (Merck and Co., Inc.) with a cumulative data base in SAS format, which contained all information on headache experience for the migraine strikes questionnaire.

\section{Statistical methods}

To assess the factors associated with early treatment patterns, questions evaluated included pain severity and associated symptoms, activities at onset of migraine, timing and selection of medication, physician-level variables, and co-morbid headache diagnoses. Logistic regression was used to identify factors associated with early treatment; adjustments were made for covariates. Chi-square and Student's $t$ tests were used for univariate analysis, where appropriate, and a binary logistic regression model using backward elimination was used for multivariate analyses. The dependent variable was "Treat early" (defined as treating within $1 \mathrm{~h}$ of headache onset), and candidate independent variables were those determined to be clinically relevant and/or which had a trend toward significance $(P<0.1)$ on univariate analysis.

To assess reasons for not treating early even when desiring to do so, data were collected for questions about whether the attack was treated when desired ("Did you want to take your medication earlier than you actually did?"), factors that may have prevented earlier treatment ("What prevented you from taking the medication sooner?"), physician specialty ("Are you currently seeing any of the following physicians for your headaches?"), physician education regarding early treatment ("Has your physician ever instructed or advised you to take your migraine medications 'early' when the pain is still 'mild'?") and satisfaction with pain relief ("How satisfied were you with the pain relief you achieved with the medication you took for this migraine attack?").

Descriptive statistics were used to examine factors potentially hindering earlier treatment and Chi-square tests were used to examine univariate associations.

\section{Results}

\section{Early treatment}

Table 1 shows patient demographics and baseline characteristics. Of the 2,001 migraineurs who participated (mean age $42.7,74.2 \%$ female), 1,856 (92.8\%) reported at least one associated symptom (nausea, vomiting, photophobia, or phonophobia) at headache onset during their attack, providing supporting evidence that participants were correct in their ascertainment of migraine. Of the 1,752 participants who provided information on treatment timing, 1,044 treated their migraine early (i.e., within $1 \mathrm{~h}$ of headache onset) (59.6\%).

Univariate analysis (Table 2) showed that factors significantly positively associated with treating early included increasing age, male gender, doing something for fun/leisure at onset, presence of photophobia, diagnosis of migraine with aura, physician advice about early treatment, and regular adherence to physician's instructions. Patients were significantly less likely to treat early if they 
Table 1 Patient demographics and baseline characteristics

\begin{tabular}{|c|c|}
\hline Baseline characteristics & $N=2,001$ \\
\hline Mean age, years (SD) & $42.7(11.7)$ \\
\hline Female $(\%)$ & 74.2 \\
\hline \multicolumn{2}{|l|}{ Associated symptoms (\%) } \\
\hline Photophobia & 81.0 \\
\hline Phonophobia & 77.7 \\
\hline Nausea & 58.4 \\
\hline Vomiting & 11.7 \\
\hline At least one of the above & 92.8 \\
\hline \multicolumn{2}{|l|}{ Initial treatment chosen $(\%)$} \\
\hline None & 0.0 \\
\hline Over-the-counter (OTC) & 12.6 \\
\hline Triptan & 62.3 \\
\hline Other prescription & 25.1 \\
\hline Age at first migraine, years (SD) & $23.2(11.3)$ \\
\hline Age at diagnosis, years (SD) & $27.1(11.0)$ \\
\hline \multicolumn{2}{|l|}{ Migraine type (\%) } \\
\hline With aura & 44.1 \\
\hline Without aura & 55.9 \\
\hline \multicolumn{2}{|l|}{ General migraine severity $(\%)$} \\
\hline Mild & 2.9 \\
\hline Moderate & 42.1 \\
\hline Severe & 55.0 \\
\hline \multicolumn{2}{|l|}{ Migraines per month (\%) } \\
\hline$\leq 2$ & 34.8 \\
\hline $3-4$ & 25.0 \\
\hline $5-8$ & 19.5 \\
\hline$\geq 9$ & 20.7 \\
\hline \multicolumn{2}{|l|}{ Employment status (\%) } \\
\hline Full-time & 48.2 \\
\hline Part-time & 12.4 \\
\hline Student or unemployed & 39.4 \\
\hline \multicolumn{2}{|l|}{ Education level (\%) } \\
\hline High school or less & 17.5 \\
\hline Some college & 38.8 \\
\hline College or graduate degree & 43.7 \\
\hline \multicolumn{2}{|l|}{ Prescription drug coverage $(\%)$} \\
\hline Yes & 87.4 \\
\hline No & 12.6 \\
\hline \multicolumn{2}{|l|}{ Other headache type } \\
\hline Tension-type & 79.4 \\
\hline Cluster & 36.4 \\
\hline Chronic daily (>15/month) & 33.6 \\
\hline Sinus & 66.6 \\
\hline
\end{tabular}

$S D$ standard deviation

were at work or school at the time of migraine onset, or if they had co-morbid tension-type and/or chronic daily headache.
Table 2 Univariate analysis: early treatment

Demographic characteristics

Treat early $(\%)$

$N=1,752$

Age

$<30, n=293$

52.9

$30-39, n=469$

56.3

$40-49, n=515$

59.8

$50-59, n=339$

64.3

$\geq 60, n=136$

72.8

$P$-value

$<0.001$

Gender

Female, $n=1,291$

Male, $n=461 \quad 64.0$

$P$-value $\quad 0.025$

Employment status

Full-time, $n=847 \quad 60.1$

Part-time, $n=216$

Student or unemployed, $n=689 \quad 60.4$

$P$-value

0.353

Education level

High school degree or less, $n=305 \quad 57.1$

Some college, $n=681 \quad 59.5$

College graduate, $n=766 \quad 60.7$

$P$-value $\quad 0.544$

Prescription drug insurance

Yes, $n=1,551 \quad 60.2$

No, $n=201 \quad 54.7$

$P$-value $\quad 0.135$

When your migraine began, were you...?

At work or school?

Yes, $n=248 \quad 52.0$

No, $n=1,504 \quad 60.8$

$\begin{array}{ll}P \text {-value } & 0.009\end{array}$

Doing something for fun or leisure?

Yes, $n=676$

No, $n=1,076 \quad 57.3$

$P$-value $\quad 0.012$

In a private place?

Yes, $n=1,256$

No, $n=496$

$P$-value 0.302

A critical member of the task at hand?

Yes, $n=779 \quad 58.3$

No, $n=973$

$P$-value $\quad 0.318$

Doing something as part of your daily routine?
Yes, $n=1,316$
59.6
No, $n=436$
59.6
$P$-value
0.963

Associated symptoms 
Table 2 continued

\begin{tabular}{|c|c|}
\hline Demographic characteristics & Treat early $(\%)$ \\
\hline \multicolumn{2}{|l|}{ Nausea } \\
\hline Yes, $n=1,042$ & 60.4 \\
\hline No, $n=710$ & 58.5 \\
\hline$P$-value & 0.423 \\
\hline \multicolumn{2}{|l|}{ Vomiting } \\
\hline Yes, $n=212$ & 57.6 \\
\hline No, $n=1,540$ & 59.9 \\
\hline$P$-value & 0.518 \\
\hline \multicolumn{2}{|l|}{ Photophobia } \\
\hline Yes, $n=1,428$ & 61.1 \\
\hline No, $n=324$ & 53.1 \\
\hline$P$-value & 0.008 \\
\hline \multicolumn{2}{|l|}{ Phonophobia } \\
\hline Yes, $n=1,364$ & 60.1 \\
\hline No, $n=388$ & 57.7 \\
\hline$P$-value & 0.398 \\
\hline \multicolumn{2}{|l|}{ Medication } \\
\hline \multicolumn{2}{|l|}{ First medication used } \\
\hline Triptan, $n=1,091$ & 60.1 \\
\hline Non-triptan prescription, $n=440$ & 60.2 \\
\hline OTC, $n=221$ & 55.7 \\
\hline$P$-value & 0.444 \\
\hline \multicolumn{2}{|l|}{ Migraine characteristics } \\
\hline \multicolumn{2}{|l|}{ Migraine type } \\
\hline With aura, $n=781$ & 63.8 \\
\hline Without aura, $n=971$ & 56.2 \\
\hline$P$-value & 0.001 \\
\hline \multicolumn{2}{|l|}{ Migraines per month } \\
\hline$\leq 2, n=593$ & 59.4 \\
\hline $3-4, n=439$ & 59.7 \\
\hline $5-8, n=352$ & 61.7 \\
\hline$\geq 9, n=368$ & 52.9 \\
\hline$P$-value & 0.782 \\
\hline \multicolumn{2}{|l|}{ General migraine severity } \\
\hline Mild, $n=40$ & 60.0 \\
\hline Moderate, $n=714$ & 59.8 \\
\hline Severe, $n=464$ & 59.4 \\
\hline$P$-value & 0.986 \\
\hline \multicolumn{2}{|l|}{ Presence of prodromal symptoms } \\
\hline Yes, $n=942$ & 58.6 \\
\hline No, $n=717$ & 61.5 \\
\hline Do not know, $n=93$ & 54.8 \\
\hline$P$-value & 0.309 \\
\hline \multicolumn{2}{|l|}{ Other headache type } \\
\hline \multicolumn{2}{|l|}{ Tension-type } \\
\hline Yes, $n=1,384$ & 57.7 \\
\hline No, $n=368$ & 66.9 \\
\hline$P$-value & 0.001 \\
\hline
\end{tabular}

Table 2 continued

\begin{tabular}{ll}
\hline Demographic characteristics & Treat early $(\%)$ \\
\hline Cluster & \\
Yes, $n=646$ & 60.4 \\
No, $n=1,106$ & 59.1 \\
$P$-value & 0.610 \\
Chronic daily $(>15 /$ month) & \\
Yes, $n=583$ & 54.6 \\
No, $n=1,169$ & 62.1 \\
$P$-value & 0.002 \\
Sinus & \\
Yes, $n=1,153$ & 58.5 \\
No, $n=599$ & 61.8 \\
$P$-value & 0.180 \\
Physician-related variable & \\
Physician specialty & \\
Primary care, $n=1,260$ & $750(59.5)$ \\
Specialist, $n=403$ & $245(60.8)$ \\
Others, $n=89$ & $49(55.1)$ \\
$P$-value & 0.605 \\
Physician advisement regarding treat early & \\
Yes, $n=1,447$ & $889(61.4)$ \\
No, $n=305$ & $155(50.8)$ \\
$P$-value & $<0.001$ \\
Regular adherence to physician's instructions & \\
Rarely/sometimes, $n=343$ & $<0.001$ \\
Most of the time/always, $n=1,361$ & \\
$P$-value & \\
\hline & \\
&
\end{tabular}

After adjusting for age, gender, and pain severity, multivariate analysis showed that early treatment was significantly positively associated with leisure activity at onset [odds ratio (OR) 1.32, $P=0.010]$, photophobia (OR 1.39, $P=0.013$ ), diagnosis of migraine with aura (OR 1.36, $P=0.004)$, prior early treatment instruction by a physician (OR 1.75 , $P<0.001)$, regular adherence to physicians' instructions (OR 2.31, $P<0.001$ ). Early treatment was significantly negatively associated with co-morbid tension and/or chronic daily headaches (OR 0.68, $P=0.004$ and OR 0.78 , $P=0.022$, respectively) (Table 3 ). Being at work or school at onset did not retain a significant association with early treatment in the multivariate analysis.

Reasons for not treating earlier

Of the 2,001 migraineurs who completed the survey, 840 $(42.0 \%)$ reported willingness to treat their migraine earlier. Among the 764 patients who wanted to treat earlier and who also provided information on treatment timing, $379(49.6 \%)$ treated within $1 \mathrm{~h}$ of headache onset, compared with $67.3 \%$ of patients who did not want to treat 
Table 3 Multivariate analysis: early treatment

\begin{tabular}{|c|c|c|c|}
\hline Variable & $\begin{array}{l}\text { Adjusted } \\
\text { OR }\end{array}$ & $\begin{array}{l}95 \% \\
\mathrm{CI}\end{array}$ & $P$-value \\
\hline Age (continuous) & 1.02 & $1.01-1.03$ & $<0.001$ \\
\hline Female & 0.81 & $0.64-1.02$ & 0.071 \\
\hline $\begin{array}{l}\text { Pain severity at onset (none, } \\
\text { mild, moderate, severe) }\end{array}$ & 0.89 & $0.77-1.02$ & 0.096 \\
\hline Leisure activity at onset & 1.32 & $1.07-1.62$ & 0.010 \\
\hline Photophobia & 1.39 & $1.07-1.81$ & 0.013 \\
\hline Migraine with aura (vs. all others) & 1.36 & $1.10-1.67$ & 0.004 \\
\hline Tension headaches & 0.68 & $0.53-0.89$ & 0.004 \\
\hline Chronic daily headaches & 0.78 & $0.63-0.96$ & 0.022 \\
\hline Physician early treatment instruction & 1.75 & $1.33-2.30$ & $<0.001$ \\
\hline $\begin{array}{l}\text { Regular adherence to } \\
\text { physician's instructions } \\
\text { (most of the time/always vs. } \\
\text { rarely/sometimes) }\end{array}$ & 2.31 & $1.80-2.96$ & $<0.001$ \\
\hline
\end{tabular}

OR odds ratio

earlier $(P<0.001)$. Of those who desired earlier treatment, the median time to treatment was $60 \mathrm{~min}$, compared with 20 min among patients who did not want to treat earlier $(P<0.001)$ (Fig. 1). The most commonly stated reason for not treating when wanted was the desire to reserve medication for a severe migraine (51.2\%). Other reasons included not having medication on hand (34.9\%), health plan quantity limit on drugs $(27.0 \%)$, inability to swallow because of nausea (18.7\%), not having access to fluid (17.3\%), and not having privacy (13.5\%) (Fig. 2).

Desire to treat earlier was not significantly associated with physician education regarding early treatment; $82.1 \%$ among those desiring to treat early reported having been educated about early treatment by their physician versus $80.3 \%$ among those who did not want to treat earlier ( $P=0.293)$. Likewise, between-group differences were not significant based on physician specialty (71.4 vs. $70.8 \%$ seeing a primary care physician, $P=0.760 ; 22.7$ vs. $22.1 \%$ seeing a headache specialist, $P=0.750$; and 5.8 vs. $7.1 \%$ seeing other or no physician, $P=0.273$ ). Desire to treat earlier was associated with dissatisfaction with pain relief (18.6 vs. $14.3 \%, P=0.015$ ).

\section{Discussion}

Early treatment of migraine has been shown to be particularly beneficial compared with treating $>1 \mathrm{~h}$ after onset of pain, but it is known that not all patients take advantage of this benefit. To elucidate the possible reasons, which might then indicate paths forward in terms of helping patients maximize the benefit of migraine treatment, data from this
Time from Headache Onset to Medication Therapy

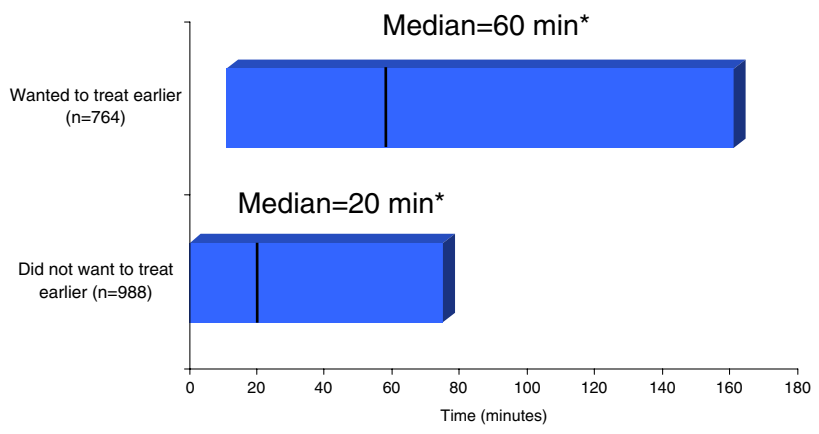

Fig. 1 Time from headache onset to first dose of medication.* $P<0.001$ for difference between medians

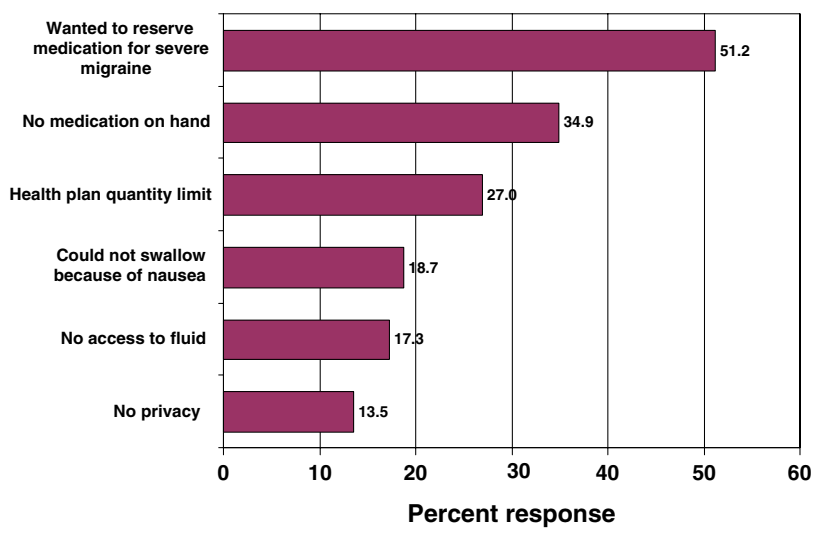

Fig. 2 Factors preventing early treatment among those who sought it $(n=840)$

questionnaire were assessed to answer two main questions about early treatment among a sample population of migraineurs. First, the analysis assessed what proportion of patients treated their headache within $1 \mathrm{~h}$ of onset; second, among those who did not treat their migraine as early as they wanted to, the data were evaluated to help determine why not. Within $24 \mathrm{~h}$ of resolution of a headache, patients reported the circumstances of the migraine attack, including their physical location and time when the migraine occurred, their activities at migraine onset, and medication use. Patients also provided information on their personal migraine history and its treatment, presence of migraineassociated symptoms, and current headache frequency and severity.

The analysis found that more than half (approximately $60 \%$ ) of patients treated their headache within an hour of its onset; thus, about $40 \%$ of patients waited more than an hour after the onset of pain to take therapy for the migraine. These results are in accord with those of Gallagher et al. [15], who also reported that prescription medications were delayed in $40 \%$ of migraine episodes, and Foley et al. [14], 
who reported that migraine medications were delayed by $49 \%$ of patients. These findings clearly indicate a need to address potential reasons for delays in treatment, in order to ensure that as many patients as possible are able to optimize their use of treatment.

To obviate unwanted delays, it is useful to understand specific reasons that patients, who may indeed know that early treatment is beneficial, nevertheless may not be taking their medication as early as possible. About $42 \%$ of patients indicated that they wanted to treat their migraine earlier than they actually did. Of those who expressed desire for earlier treatment, only about half treated their most recent migraine within an hour. The desire to reserve medication for a severe migraine was the most common reason given for delaying treatment, reported in fully half the patients who wanted to treat earlier. The next most common reason, reported in one-third of patients, was not having the medication on hand, and about one quarter of the patients said that their health plan quantity limit on drugs prevented them from treating as early as they wanted; additional reasons included nausea interfering with the ability to swallow, lack of access to fluid, and lack of privacy.

These results are in general agreement with the small amount of prior work that has previously been done in this area. In the aforementioned survey by Gallagher et al. [15], the authors reported that the most common reasons for delaying prescription medication use were medication access issues, limited numbers of pills, difficulties in functioning, and concerns about adverse events. Interestingly, Gallagher did not report on what we found to be the most commonly reported reason for delay: the desire to reserve medications for severe migraine. This commonly cited reason for treatment delay was also observed by Foley et al. [14]. Of patients who reported delayed treatment, $70 \%$ cited wanting to wait and see if the attack was really a migraine attack as a reason for the delay, and $46 \%$ cited wanting to take medication only for a severe attack.

Despite the observed high rate of reported migraineassociated symptoms at headache onset, we observed that patients with other co-morbid primary headaches were more likely to delay treatment. Epidemiologic research has shown that up to $90 \%$ of migraine patients also suffer from tension-type headache [16] and migraine and tension-type headaches share many important similarities [17]. To optimize migraine care, physicians should routinely educate their patients about early migraine symptoms, particularly for patients recently diagnosed with migraine, in addition to prescribing appropriate medications. Both Gallagher and Foley also found concern about medication side effects as a factor in treatment delay, reported by 15 and $37 \%$, respectively. Our study did not directly explore fear of side effects as a potential reason for delaying treatment.
Some of the stated reasons for treatment delay can be addressed with practical adjustments, such as carrying medication when leaving home. Alternative formulations (e.g., rapidly dissolving tablet, nasal spray) can be considered in patients prone to migraine-associated nausea or who are frequently on the go and may not have continuous access to water or other liquids. However, solutions to the most commonly reported obstacles are not straightforward. For example, in patients with other types of headaches and/ or chronic daily headache, the advantages and disadvantages of early treatment must be carefully weighed, bearing in mind that frequent use of certain acute migraine medications may predispose to medication overuse headache and chronic migraine [18].

Several factors act as limitations on the analysis of reasons for delayed treatment. It is possible that the retrospective desire to treat earlier may be influenced by severity of headache pain and/or any associated symptoms the patient may have experienced. Thus, the wish itself to treat earlier may not have emerged until after the first hour of migraine. Moreover, the survey does not account for the fact that reasons for not treating may vary by attack, within the same patient. For example, on two different occasions in which a migraine begins, a patient may have considerably easier access to medication in one situation versus the other. In addition, other practical considerations that could interfere with timely treatment may not have been captured by this survey.

In summary, a large proportion of migraine patients did not treat their headache within the first hour of headache onset. The study found that the most common reasons for the delay in treatment were (1) a wish to reserve the medication for a severe migraine, and (2) lack of easy access to the medication. Finding ways to overcome these and other practical obstacles preventing patients from medicating early may help a greater number of patients to relieve their migraines faster.

Acknowledgments Merck and Co., Inc. funded the study. Drs. Golden and $\mathrm{Hu}$ are employees of Merck and Co., Inc. who may potentially own stock and/or hold stock options in the company. Dr. Evans was an employee of Merck during the conduct of this study and the writing of this manuscript.

Conflict of interest Drs. Golden and Hu are employees of Merck and Co., Inc., and may own stock or stock options in the company. Dr. Evans was an employee of Merck during the conduct of this trial and the writing of this manuscript, and may own stock in the company.

\section{References}

1. Lipton RB, Stewart WF, Diamond S, Diamond ML, Reed M (2001) Prevalence and burden of migraine in the United States: data from the American Migraine Study II. Headache 41:646657 
2. Kelman L (2005) Validation of the classification of migraine with aura (IHS A1.1) proposed in ICHD-2. Headache 45:1339-1344

3. Martin VT, Penzien DB, Houle TT, Andrew ME, Lofland KR (2005) The predictive value of abbreviated migraine diagnostic criteria. Headache 45:1102-1112

4. Mulleners WM, Aurora SK, Chronicle EP, Stewart R, Gopal S, Koehler PJ (2001) Self-reported photophobic symptoms in migraineurs and controls are reliable and predict diagnostic category accurately. Headache 41:31-39

5. Silberstein SD (1995) Migraine symptoms: results of a survey of self-reported migraineurs. Headache 35:387-396

6. Giffin NJ, Ruggiero L, Lipton RB, Silberstein SD, Tvedskov JF, Olesen J et al (2003) Premonitory symptoms in migraine. An electronic diary study. Neurology 60:935-940

7. Kelman L (2004) The premonitory symptoms (prodrome): a tertiary care study of 893 migraineurs. Headache 44:865-872

8. Mannix L (2008) A review of the 5HT1B/1D agonist rizatriptan: update on recent research and implications for the future. Expert Opin Pharmacother 9:1001-1011

9. Ng-Mak DS, Hu XH, Chen Y, Ma L, Solomon G (2007) Times to pain relief and pain freedom with rizatriptan $10 \mathrm{mg}$ and other oral triptans. Int J Clin Pract 61:1091-1111

10. Moschiano F, D'Amico D, Allais G, Rigamonti A, Melzi P, Schieroni F et al (2005) Early triptan intervention in migraine: an overview. Neurol Sci 26(Suppl 2):s108-s110

11. Hu XH, Raskin NH, Cowan R, Markson LE, Berger ML, On behalf of The United States Migraine Study Protocol (USMAP)
Group (2002) Treatment of migraine with rizatriptan: when to take the medication. Headache 42:16-20

12. Cady RK, Sheftell F, Lipton RB, O'Quinn S, Jones M, Putnam DG et al (2000) Effect of early intervention with sumatriptan on migraine pain: retrospective analyses of data from three clinical trials. Clin Ther 22:1035-1048

13. Cady R, Martin V, Mauskop A, Rodgers A, Hustad CM, Ramsey $\mathrm{KE}$ et al (2006) Efficacy of rizatriptan $10 \mathrm{mg}$ administered early in a migraine attack. Headache 46:914-924

14. Foley KA, Cady R, Martin V, Adelman J, Diamond M, Bell CF et al (2005) Treating early versus treating mild: timing of migraine prescription medications among patients with diagnosed migraine. Headache 45:538-545

15. Gallagher RM, Kunkel R (2003) Migraine medication attributes important for patient compliance: concerns about side effects may delay treatment. Headache 43:36-43

16. Lyngberg AC, Rasmussen BK, Jørgensen T, Jensen R (2005) Has the prevalence of migraine and tension-type headache changed over a 12-year period? A Danish population survey. Eur J Epidemiol 20:243-249

17. Cady R, Schreiber C, Farmer K, Sheftell F (2002) Primary headaches: a convergence hypothesis. Headache 42:204-216

18. Dodick D, Freitag F (2006) Evidence-based understanding of medication-overuse headache: clinical implications. Headache 46(Suppl 4):S202-S211 